\title{
Rankings globais, qualidade e a convergência com a internacionalização da Educação Superior na América Latina
}

Global rankings, quality and convergence with the internationalization of Higher Education in Latin America

\section{Rankings globales, calidad y convergencia con la internacionalización de la Educación Superior en América Latina}

\author{
Marilene Gabriel Dalla Corte ${ }^{1}$ \\ Fernanda Ziani Mendes ${ }^{1}$
}

DOI: http://dx.doi.org/10.20435/serie-estudos.v0i0.1368

\begin{abstract}
Resumo: Este estudo, realizado no bojo das pesquisas do Grupo Gestar/CNPq/UFSM, refere-se à temática de internacionalização da Educação Superior (ES) e se insere no debate sobre os rankings e a qualidade. Tem por objetivo geral traçar um panorama sobre a convergência entre os indicadores definidos em destacados rankings globais, os quais buscam medir a qualidade a partir das ações de internacionalização e a interlocução com a percepção latino-americana. Caracteriza-se por uma pesquisa bibliográfica de abordagem qualitativa, com fulcro em revisão teórica, averiguação das declarações emitidas em conferências regionais e mundiais e relatórios de organismos internacionais, a exemplo da UNESCO e do Banco Mundial. No mundo globalizado, a universidade se posiciona como um dos atores estratégicos que contribuem para o desenvolvimento. Assim, estabelecem-se a sociedade do conhecimento e o fortalecimento do processo de mercantilização da ES. Com o avanço da transnacionalização, os rankings internacionais se propõem a classificar as melhores instituições. Verificou-se que os mais influentes rankings globais têm critérios próprios, tais como a produtividade da pesquisa e as citações. Sob a lente de teóricos e da UNESCO, a qualidade é um conceito multidimensional que requer reflexão constante e que deve estar articulada com a pertinência. Constatou-se que a garantia de qualidade, sob a perspectiva do capitalismo universitário, tende a valorizar a ES como commodity, mais do que, propriamente, alcançar um conceito determinado de "qualidade" de ensino.
\end{abstract}

Palavras-chave: internacionalização; Educação Superior; rankings globais.

\footnotetext{
${ }^{1}$ Universidade Federal de Santa Maria (UFSM), Santa Maria, Rio Grande do Sul, Brasil.
} 
Abstract: This study, conducted in the field of research by the Gestar/CNPq/UFSM Group, refers to the theme of internationalization of Higher Education (ES) and is inserted in the debate on rankings and quality. Its general objective is to draw an overview of the convergence between the indicators defined in outstanding global rankings, which seek to measure quality from internationalization actions and the dialogue with Latin American perception. It is characterized by a bibliographical research of qualitative approach, with fulcrum in theoretical review, investigation of the statements issued at regional and world conferences and reports of international organizations, such as UNESCO and the World Bank. In the globalized world, the university is positioned as one of the strategic actors that contribute to development. Thus, the knowledge society is established and the process of commodification of ES is strengthened. With the advance of transnationalization, the international rankings propose to classify the best institutions. It was found that the most influential global rankings have their own criteria, such as research productivity and citations. Under the lens of theorists and UNESCO, quality is a multidimensional concept that requires constant reflection and that must be articulated with pertinence. It was found that quality assurance, from the perspective of university capitalism, tends to value Higher Education as a commodity, rather than properly achieving a determined concept of "quality" of teaching.

Keywords: internationalization; Higher Education; global rankings.

Resumen: Este estudio, realizado en el campo de la investigación del Grupo Gestar/CNPq/UFSM, se refiere al tema de la internacionalización de la Educación Superior (ES) y se inserta en el debate sobre rankings y calidad. Su objetivo es trazar una visión general de la convergencia entre los indicadores definidos en los rankings mundiales destacados, que buscan medir la calidad desde las acciones de internacionalización y el diálogo con la percepción latinoamericana. Se caracteriza por una investigación bibliográfica de enfoque cualitativo, con fulcro en revisión teórica, investigación de las declaraciones emitidas en conferencias regionales y mundiales e informes de organizaciones internacionales, como la UNESCO y el Banco Mundial. En el mundo globalizado, la universidad se posiciona como uno de los actores estratégicos que contribuyen al desarrollo. Así, se establece la sociedad del conocimiento y se fortalece el proceso de mercantilización de la ES. Con el avance de la transnacionalización, los rankings internacionales proponen clasificar a las mejores instituciones. Se encontró que los rankings mundiales más influyentes tienen sus propios criterios, como la productividad de la investigación y las citas. Bajo la mirada de los teóricos y la UNESCO, la calidad es un concepto multidimensional que requiere una reflexión constante y que debe articularse con pertinencia. Se encontró que la garantía de calidad, desde la perspectiva del capitalismo universitario, tiende a valorar la Educación Superior como una commodity, en lugar de, correctamente, lograr un concepto determinado de "calidad" de la enseñanza.

Palabras clave: internacionalización; Educación Superior; rankings mundiales.

\section{INTRODUÇÃO}

O trajeto que os países enfrentam para atingir padrões de desenvolvimento econômico e social apresenta diversos desafios, entre eles, a inovação tecnológica e a consequente inserção, com sucesso, no mundo globalizado. Para alcançar tal propósito, estabelecem-se a sociedade do conhecimento e a economia do 
conhecimento, tomando como referência as diretrizes emanadas por organismos internacionais por meio de seus relatórios. Notadamente, a dependência que muitos países possuem em relação a organismos como o Banco Mundial e a Organização para a Cooperação e o Desenvolvimento Econômico (OCDE) é o parâmetro para que eles submetam suas políticas públicas às condicionalidades para o recebimento de fomento.

A tão idealizada globalização tem sido analisada sob a lente de diferentes áreas. Segundo Ball (2001), vale analisar o futuro do Estado-Nação a partir da manutenção ou não da autonomia política e econômica diante de tal influência, pela perspectiva da transformação cultural influenciada pela mídia global e, ainda, pela transformação social à medida que se prioriza o imediatismo e o substituível facilmente.

Torres (2016) ensina que é possível estudar a globalização a partir de oito pontos de vista. Inicialmente, é possível destacar a globalización desde arriba, que vem delimitada pelo neoliberalismo pontuado pela Organização Mundial do Comércio (OMC), e a globalización desde abajo, ou antiglobalização, que é representada por movimentos que se opõem à globalização corporativa. Diferentemente da ótica do mercado, encontra-se a globalização dos direitos humanos, a qual se apresenta em um panorama de cidadania global e de democracia e encontra espaço nas legislações. Há a globalização demarcada pela hibridez cultural. Também, a globalização que vem desenhada sobre os conceitos de sociedade da informação, que transforma o mundo por meio do avanço da tecnologia da informação e impacta na sociedade de maneira que o conhecimento passa a ser mais um fator de produção junto da terra, do trabalho, do capital e da tecnologia. Já a globalização da sociedade em rede é aquela em que o conhecimento passa a ser difundido por qualquer cidadão, e não apenas por estudiosos. Por outro lado, Torres (2016), registra a globalização da guerra internacional contra o terrorismo, em que a liberdade está intimamente conectada à segurança. Por fim, o autor relembra que há a globalização do terrorismo.

As universidades compõem esse cenário e se posicionam como atores estratégicos no que concerne à responsabilidade social e ao impulso ao desenvolvimento. É uníssono o discurso em torno da necessidade de educação de qualidade, todavia sua conceituação depende da perspectiva de quem a define. A tendência mundial avança no sentido da mercantilização do Ensino Superior, 
sendo fortalecida pela transnacionalização das universidades, a qual se mostra um dos vetores da internacionalização. O ingresso da Educação Superior (ES) com força no mercado financeiro impacta no avanço dos rankings globais, os quais passam a ser considerados mecanismos para a medição da "qualidade" ofertada nas universidades.

Sob a lente de Perrota (2015) e Vera (2015), a internacionalização da ES encontra tensões a partir das orientações de caráter exógeno e endógeno. Em um cenário de internacionalização exógena, a qualidade se relaciona diretamente com a sociedade do conhecimento "nominal", que foca no conhecimento para fins econômicos. Nessa perspectiva, os organismos internacionais OCDE, OMC, Banco Mundial e Organização das Nações Unidas para a Educação, a Ciência e a Cultura (UNESCO) tentam imprimir seus conceitos de qualidade dentro do processo de transnacionalização, ou seja, livre circulação do conhecimento, não estando restrito ao Estado-Nação. Tal situação embasa o debate sobre a qualidade isomórfica nas universidades, a qual sofre a influência dos organismos internacionais a partir da percepção da Educação Superior como serviço educacional, e não como bem público (MOROSINI, 2014). Segundo Morosini (2009; 2014), a qualidade isomórfica baliza a formação acadêmica com foco na empregabilidade e em profissionais competitivos, estando fortemente conectada a parâmetros universais ditados por rankings internacionais e não respeitando os princípios do Estado de dizer o que é qualidade na educação.

Sob o enfoque da internacionalização endógena, apregoa-se a relevância da cooperação horizontal para que a qualidade da Educação Superior seja avaliada a partir da equidade, da inclusão social, da diversidade e da pertinência local e regional, características alinhadas ao exercício da cidadania e ao direito à educação.

Notadamente, o processo de construção pelo qual passam as políticas nacionais são resultado das influências globais e locais, as quais se refletem na definição de qualidade na educação, nas políticas do Ensino Superior e nas decisões institucionais (BALL, 2001). A conjuntura atual deflagra o crescimento dos rankings e das tabelas de classificação, com vistas a posicionar instituições de Ensino Superior em todo o mundo.

Em face do exposto, a problemática da investigação está delineada a partir do cenário de mercantilização e transnacionalização das universidades, no contexto da globalização e aferição de "qualidade" a partir de critérios de produtividade. 
Este estudo tem por objetivo geral traçar um panorama sobre a convergência entre os indicadores definidos em destacados rankings globais, os quais buscam medir a qualidade a partir ações de internacionalização, e a interlocução com a percepção latino-americana.

\section{METODOLOGIA}

Para atingir o propósito deste estudo, metodologicamente, priorizou-se uma pesquisa básica, de abordagem qualitativa (GIL, 2002). Caracteriza-se por um caráter exploratório, visto que se buscou refletir sobre a temática a partir de um levantamento bibliográfico preliminar, respaldado em fontes secundárias, tais como: livros, periódicos científicos, declarações emanadas em conferências regionais e mundiais sobre a ES e relatórios de organismos internacionais. Em sua maioria, o material está disponibilizado em formato eletrônico.

O processo de desenvolvimento da investigação foi desenhado em duas seções. A primeira seção oferece uma síntese sobre os rankings, contendo uma breve revisão teórica acerca da temática e complementada por informações institucionais disponibilizadas em páginas da Web dos principais rankings globais e seus indicadores para a internacionalização. O critério de seleção dos rankings, a serem cotejados neste estudo, tomou em consideração o reconhecimento destes como referências globais e as discussões promovidas na agenda da comunidade acadêmica internacional, conforme ensinamentos de Albornoz e Osorio (2018) e Barsky (2014).

Na segunda seção, são examinados os conceitos de qualidade, a partir da percepção de estudiosos e dos posicionamentos emanados em documentos emitidos pelo Banco Mundial e pela UNESCO. Tais organismos internacionais exercem forte influência na condução das políticas públicas, especialmente em países em desenvolvimento, motivo pelo qual aportam significância ao deslinde desta temática.

\section{UMA SÍNTESE SOBRE OS RANKINGS}

Segundo Albornoz e Osorio (2018), o sistema de Educação Superior americano teve influência na criação dos rankings, à medida que impactavam nas escolhas dos estudantes, os quais definiam seus estudos universitários de acordo com suas 
necessidades e condições. Hazelkorn (2017) complementa que o surgimento dos rankings se relaciona com a situação social e política de cada época e se divide em quatro fases, sendo a primeira demarcada pelo período de 1900-1950 e a segunda fixada entre os anos de 1959 e 2000, tendo destaque os rankings nacionais em resposta ao mercado. A terceira fase, registrada a partir do ano de 2003, é realçada pelos rankings globais que tomam espaço como resposta à globalização. Estabelecida a partir do ano de 2008, a atual e quarta fase se caracteriza pelos rankings supranacionais, uma vez que a internacionalização do Ensino Superior traz implícita a necessidade de avaliar a qualidade da oferta transnacional.

Barsky (2014) ensina que a organização das classificações dos rankings tem também origem desportiva e, para tanto, agrega dados a partir de critérios. Em sua opinião, tal situação não é tão facilmente transferida para as universidades, instituições complexas em que transbordam saberes de diferentes áreas do conhecimento, o que, por si só, dificulta classificações internas e, naturalmente, tende a tornar-se uma árdua tarefa se analisada e comparada de maneira planetária.

Sob a lente de Salmi e Saroyan (2009), o foco na credibilidade e o incremento na quantidade de rankings são justificados pelo aumento de matrículas, pelo alto número de instituições de Ensino Superior privadas no exterior, pelo ensino a distância, pela internacionalização da ES e pela demanda por mantenedores. $O$ fenômeno dos rankings influencia não apenas estudantes, mas governos, organismos internacionais e mercado.

Existe uma vasta gama de rankings, os quais podem ser distribuídos por conceitos, metodologias, propósitos e regiões. Os rankings unidimensionais definem um peso específico para cada indicador, os multidimensionais oferecem tabelas de pontuações para os indicadores e tornam a análise personalizada. No que concerne às fontes de informações, tais ranqueamentos podem partir de pesquisas de opinião ou de dados bibliométricos. Por outro lado, há os rankings nacionais e regionais, que comparam universidades de determinados países, e os rankings globais, que comparam IES de diferentes regiões do mundo (ALBORNOZ; OSORIO, 2018).

Para Barsky (2014), os rankings globais, universais ou internacionais tomaram proporção com o crescimento da internacionalização, com os processos de mercantilização da ES e as diferentes modalidades de fomento e gestão universitária que exigem dados de desempenho. 
Rankings globais, qualidade e a convergência com a internacionalização da Educação Superior na América Latina

É sob esse panorama que se propõe reconhecer como os rankings globais se articulam com os conceitos de qualidade.

As análises de diferentes teóricos anunciam que os rankings classificam, a partir de metodologias específicas, as "melhores instituições". Hazelkorn (2017) entende que os critérios adotados por tais rankings atendem a interesses diversos, posicionando as universidades em um quadro comparativo e desigual, uma vez que inserem entre os indicadores números que remetem ao desempenho e à produtividade.

Não obstante os inúmeros rankings, para este estudo pode-se citar como destacados os rankings globais: Academic Ranking of World Universities (ARWU), QS World University Rankings e o Times Higher Education World University Ranking (THE).

O ARWU, ou Classificação Acadêmica das Universidades Mundiais, em português, é publicado desde 2003 pelo Centro de Universidades de Classe Mundial (CWCU), da Escola Superior de Educação (ex-Instituto de Ensino Superior) da Universidade de Jiao Tong de Xangai, na China (ARWU, 2019). Em 2019, foram 1.800 universidades classificadas e as 1.000 melhores foram divulgadas. São utilizados seis indicadores. No que se refere à qualidade da educação, são avaliados os números de ex-alunos laureados pelo Nobel e medalhistas Fields. Já no tocante à qualidade do corpo docente são indicadores: o número de funcionários que ganharam os Prêmios Nobel de Física, Química, Medicina e Economia e o Prêmio Fields Medal em Matemática; e o número de pesquisadores altamente citados, conforme análise da Clarivate Analytics. Para averiguar o desempenho das investigações, são considerados os números de artigos publicados na revista Nature and Science e a quantidade de artigos indexados pelo Science Citation Index Expanded (SCIE) e Social Science Citation Index (SSCI). O sexto indicador reflete o cálculo da performance acadêmica per capita, com as pontuações ponderadas dos cinco indicadores acima, divididos pelo número de docentes em tempo integral. No ano de 2019, observou-se que, das 20 melhores, 16 são americanas e quatro europeias. Das 1.000 classificadas, as IES dos EUA e do Reino Unido são as primeiras colocadas, seguidas da Suíça, Austrália e China (ARWU, 2019).

O inglês QS World University Rankings reúne as opiniões de especialistas sobre a qualidade do ensino e da pesquisa nas universidades do mundo, aplicando questionários para compor a sua avaliação (QS WORLD UNIVERSITY RANKINGS, 
2019). Por exemplo, a "Reputação acadêmica" compõe $40 \%$ da pontuação e avalia o ponto de vista dos acadêmicos. A "Avaliação da reputação do empregador", que equivale a $10 \%$, visa identificar as instituições de onde eles obtêm os graduados mais competentes, inovadores e eficazes. A análise da proporção "Faculdade/ Aluno" equivale a $20 \%$ e também busca avaliar a qualidade, verificando até que ponto as instituições são capazes de proporcionar aos estudantes um acesso significativo a professores e tutores, e reconhece que um elevado número de membros do corpo docente por estudante reduzirá o peso do ensino em cada acadêmico individual. Já no quesito "Citações por faculdade", que equivale a 20\%, é considerado o número total de citações recebidas por todos os trabalhos produzidos por uma instituição ao longo de um determinado período e estipulam-se valores determinados de acordo com a área de conhecimento. A relação de professores internacionais e a proporção de estudantes internacionais compõem o cálculo, com o peso de $5 \%$ em cada indicador. Sob a ótica deste Ranking, uma universidade altamente internacional possui a capacidade de atrair professores e alunos de todo o mundo, o que implica uma perspectiva global (ALBORNOZ; OSORIO, 2018).

O Times Higher Education World University Ranking, também de origem inglesa, avalia o ensino, a pesquisa, as citações, a perspectiva internacional e o ingresso da indústria (TIMES HIGHER EDUCATION [THE], 2019). A perspectiva internacional refere-se a 7,5\% e é composta pela proporção de estudantes internacionais/locais, proporção de funcionários internacional/local e a colaboração internacional. Destaca-se que as citações compõem 30\%, o que, naturalmente, reflete na internacionalização (ALBORNOZ; OSORIO, 2018).

Dado o impacto dos rankings, as questões metodológicas estão no centro das discussões acadêmicas, uma vez que as políticas nacionais e institucionais tendem a ser desenhadas de acordo com tais medidas de classificação. A inadequada utilização desses números e dados pode influenciar a opinião pública e a divisão de recursos governamentais.

Para Salmi e Saroyan (2009), comparar instituições com missões, recursos, foco ou não na pesquisa e tamanhos diferentes é uma falha metodológica. Os autores detectam, ainda, em estudo comparativo de tabelas de classificação, que as IES mais bem classificadas estão em países de língua inglesa e que as 100 melhores estão em países em que as instituições nacionais são comumente ranqueadas e, por conseguinte, podem estar mais bem desenvolvidas devido à capacidade de 
compilar dados. Ademais, as instituições que trabalham a pesquisa tendem a ser mais favorecidas do que outras que detêm o foco no ensino. Nesse sentido, Dávila (2018) entende que esse paradigma de qualidade acaba por obrigar que as IES implementem políticas institucionais que foquem o incremento de publicações, o que certamente impactará as citações do corpo docente. Entende, ainda, que essa metodologia é arcaica e duvidosa em relação aos atributos de qualidade.

De acordo com Barsky (2014), entre as limitações metodológicas desses processos, é possível destacar:

- a impossibilidade de avaliar comparativamente e em termos globais as IES que têm em suas disciplinas e cursos enfoques diversos, uma vez que cada área pode se apresentar mais desenvolvida e estar fortalecida em um determinado eixo (pesquisa ou ensino);

- esse tipo ideal de universidades de classe mundial tem a perspectiva de uma qualidade baseada nos quantitativos de investigação;

- a supremacia das publicações em inglês;

- a alta valorização de publicação em revistas científicas, situação que desfavorece áreas de Ciências Sociais e Humanas, em que a publicação de uma obra completa em formato de livro tem mais valor que um artigo em revista.

No tocante às publicações e citações, há de se considerar a complexidade que permeia as relações das revistas e consultorias internacionais. Agregue-se a isso o fato de que o Institute for Scientific Information (ISI) mede o fator de impacto das revistas científicas a partir da análise das citações, o que, na prática, pretende medir a "qualidade" das revistas e sua importância. Tal fator de impacto, todavia, enfrenta questionamentos no sentido de ser ponderado se o número de citações indicaria qualidade ou quantidade, se o curto período que é levado em consideração para calcular o número de citações seria suficiente e se esse curto período desconsideraria citações clássicas (BARSKY, 2014).

Feitas essas breves considerações sobre a perspectiva do fator "qualidade" distinguido pelos rankings, passa-se a desvelar os conceitos de qualidade da ES, a partir de teóricos e propostas emanadas por organismos internacionais e fóruns educacionais. 


\section{ALGUNS ENFOQUES PARA A QUALIDADE NA EDUCAÇÃO SUPERIOR}

Sob a lente de Morosini et al. (2016), a "qualidade" exige um exercício permanente de autorreflexão que atenda a referenciais teóricos, éticos e políticos, orientados para um processo avaliativo no qual toda a instituição possa engajar-se.

Revisando o panorama trazido sobre os rankings e alinhando ao posicionamento apregoado no relatório do Banco Mundial (2017), é inevitável considerar que as definições de qualidade na ES perpassam questões de interesse comercial. Nesse sentido, vale destacar a contribuição de Ball (2001, p. 109):

O desempenho (de sujeitos individuais ou organizações) funciona como medida de produtividade ou resultado, ou exposição de "qualidade" [...] representa a qualidade e o valor de um indivíduo ou organização num campo de avaliação.

O Banco Mundial, por sua vez, entende que a qualidade está diretamente relacionada à eficiência e eficácia e se alcançará por meio do acesso a livros, textos, equipamentos, laboratórios e formação pedagógica. Ademais, defende que os processos de ensino e aprendizagem devem ser mensurados. Para viabilizar esse caminho, disponibiliza recursos financeiros a projetos que busquem alcançar os níveis propostos de qualidade. Assim, os países periféricos que buscam tais recursos deparam-se com a necessidade de aproximarem seus projetos à perspectiva de administração da educação e capacitação de professores ditadas por esse organismo internacional, bem como se alinharem à avaliação e aos sistemas de exame, entre outras submissões (GRUPO BANCO MUNDIAL, 2017).

Em outro sentido, têm-se posicionamentos emitidos pela UNESCO em suas conferências sobre educação. A Conferência Mundial sobre Educação Superior de 1998 (CMES) declarou que a qualidade em Educação Superior é um conceito multidimensional que implica ensino e programas acadêmicos, pesquisa e fomento da ciência, provisão de pessoal, estudantes, edifícios, instalações, equipamentos, serviços de extensão à comunidade e o ambiente acadêmico em geral. A qualidade é, também, impactada pela dimensão internacional por meio do intercâmbio de conhecimentos, redes, mobilidade e projetos de pesquisa (UNESCO, 1998).

Dias (2017) revela que, em conferência ocorrida no ano de 2003, que objetivava rever os resultados da CMES de 1998, os participantes foram surpreendidos com a inclusão, no informe final, do acréscimo do adjetivo "global" à expressão "educação como bem público". A adição tem relação direta com a qualidade, 
que deverá estar adequada às exigências do mercado, e esse bem público global, conforme Dias (2017, p. 101), seria “[...] desenvolvido em um pequeno grupo de países e que passa a ser considerado como modelo de qualidade a ser imitado no mundo inteiro.". Ademais, Dias (2017, p. 92) reforça: "Os critérios de seleção centram-se na pesquisa acadêmica, sem considerar a qualidade do ensino.". O autor destaca que os rankings acadêmicos definem regras para aferir e mostrar onde há qualidade no ES, a partir do modelo de nações hegemônicas, e têm se transformado em uma indústria lucrativa. Mas o que é pior, influenciam as políticas públicas e, não raras vezes, os indicadores estão em total descompasso com a realidade dos países em desenvolvimento.

A Conferência Mundial sobre Ensino Superior de 2009 declarou que era necessário estabelecer sistemas que garantissem a qualidade e os padrões de avaliação, assim como promover a qualidade cultural dentro das instituições. Critérios de qualidade devem refletir todos os objetivos da ES, especialmente o propósito de cultivar o pensamento crítico e independente nos estudantes e a capacidade de aprender por toda a vida. Tais critérios devem estimular a inovação e a diversidade. Garantir a qualidade do Ensino Superior requer o reconhecimento da importância de se atrair e reter uma equipe de ensino e pesquisa comprometida, talentosa e qualificada (UNESCO, 2009).

O Plano de Ação da Conferência Regional de Educação Superior 2018 (UNESCO, 2018) se estabelece com o propósito de associar a qualidade da ES à equidade, inclusão social, diversidade e pertinência local e regional, características alinhadas ao exercício da cidadania e ao direito à educação. Deve-se priorizar a vinculação da ES a projetos destinados à inovação pedagógica e ao desenho pedagógico das educações básica, secundária e média. Nota-se a busca por um profissional empreendedor, inovador, com pensamento crítico e interdisciplinar, bem como um sistema educativo com visão humanista, crítica, solidária e inclusiva. Entre as estratégias para atingir tal "qualidade" são pontuados diferentes caminhos a serem explorados, tais como: políticas afirmativas de ingresso, controle de evasão e incremento do financiamento público. Ainda, propõe trajetórias curriculares flexíveis e mobilidade estudantil inclusiva com foco na democratização da ES. Um caminho conducente a novas trajetórias formativas, a partir das necessidades locais e regionais, e alinhado às novas necessidades laborais do atual contexto. 
Depreende-se do texto do Plano de Ação da CRES 2018 (UNESCO, 2018) que, inclusive, pode agregar na busca de uma educação de qualidade a inserção de grupos heterogêneos de diferentes origens culturais e sociais, fortalecida por uma formação que incorpore o enfoque transversal da identidade de gênero, da diversidade cultural e interculturalidade. Essa formação de qualidade traz em seu cerne uma perspectiva inter e intradisciplinar com pertinência, responsabilidade e compromisso social. Outra matriz é a educação continuada de todos os atores, sejam estudantes, sejam docentes e staff.

A qualidade com pertinência vem articulada com o reconhecimento de aprendizados adquiridos em caminhos formativos flexíveis. O comprometimento com uma cultura de cidadania global vem vinculada a uma formação docente com vistas a esse fim. No tocante à internacionalização, a qualidade se materializa através do perfil internacional do currículo, programas de dupla titulação, mobilidade e reconhecimento de trajetos formativos, domínio de idiomas. Ademais, a conformação de uma rede regional de avaliação, a acreditação e o reconhecimento de titulações, diplomas e trajetórias formativas de graduação e pós-graduação podem contribuir para assegurar a qualidade, sempre vinculada à ideia de pertinência e inclusão. Ao tratar do papel estratégico da ES para o desenvolvimento sustentável da região (eixo 1), o documento prevê a identificação, definição e consenso para indicadores comuns de ES (UNESCO, 2018).

Depreende-se, ainda, que o Plano de Ação da CRES 2018 adota como critério de qualidade a eficácia e a sustentabilidade para atingir os objetivos das IES, além de estar alinhado à perspectiva de sociedade do conhecimento "inteligente", em que, segundo Didriksson (2008), os valores concentram-se no exercício real da democracia, na qualidade de vida da população e na liberdade da sociedade da América Latina e Caribe para decidir como organizar o seu futuro.

Segundo o documento “Educação 2030" (UNESCO, 2016), a educação de qualidade deve promover criatividade e conhecimento, habilidades com foco para a resolução de problemas, habilidades de alto nível cognitivo e habilidades interpessoais e sociais. Ademais, deve primar por desenvolver habilidades, valores e atitudes que permitam aos cidadãos levar vidas saudáveis, tomar decisões conscientes e responder a desafios locais e globais por meio da educação para o desenvolvimento sustentável e da educação para a cidadania global. 
De acordo com Uvalic-Trumbic (2009, p. 174), as “Diretrizes para a Provisão de Qualidade no Ensino Superior Além Fronteiras", aprovadas pela UNESCO em 2005, objetivam: apoiar cooperação e compreensão internacional para garantir qualidade em geral, proteger os estudantes de IES que fornecem ES sem credenciamento apropriado e estimular o desenvolvimento de ES de qualidade. A soberania nacional com relação à garantia de qualidade e à diversidade de sistemas que isso produz em todo o mundo é um dos princípios. As parcerias, o compartilhamento, o diálogo e a confiança mútua no envio e na recepção de acadêmicos e profissionais, assegurando a qualidade, são algumas das características. Tais diretrizes trazem como fulcro a subsidiariedade e as parcerias. Por subsidiariedade, entende-se que, não obstante a globalização e internacionalização, a garantia de qualidade deve ser em nível nacional, assegurando a soberania para legislar e executar e, ainda, a articulação com governos para estipular as responsabilidades quanto à garantia de tal qualidade. Já as parcerias da comunidade e do governo devem buscar uma qualidade vinculada à sustentabilidade da ES, por meio de comunidades de prática de uma cultura de ES confiável (UVALIC-TRUMBIC, 2009).

Diante de tantas variáveis, que devem ser consideradas para avaliar as questões de qualidade na ES, especialmente para a aferição desta em rankings internacionais, o International Ranking Expert Group (IREG), fundado em 2004 pelo Centro Europeu de Educação Superior (UNESCO-CEPES) e pelo Instituto de Política de Educação Superior, apresenta-se como um observatório que visa propor um conjunto de princípios de qualidade e boas práticas em elaboração de rankings. Os Princípios de Berlim pregam, entre outras questões, que os rankings de IES devem:

* Ser uma entre várias, diferentes abordagens para a avaliação do ensino superior. [...]

* Rankings internacionais, em particular, devem estar atentos à possibilidade de viés e ser precisos na determinação do seu objetivo. Nem todas as nações ou sistemas compartilham os mesmos valores e crenças sobre o que constitui a "qualidade" em instituições de ensino superior, e os sistemas de classificação não devem ser concebidos para forçar essas comparações. [...]

* A escolha dos dados deve ser baseada no reconhecimento da capacidade 
de cada medida para representar a qualidade acadêmica e forças institucionais, e não sobre disponibilidade de dados (IREG, 2006, s.p.)2.

A tensão que permeia o debate sobre qualidade e rankings globais não é recente, tampouco de fácil equalização. Na América Latina, as conferências regionais apresentam como premissa a solidariedade e, por consequência, uma qualidade vinculada a princípios e valores humanísticos. Diferentemente, em países desenvolvidos, nota-se a priorização de qualidade ligada à produtividade e ao mundo do trabalho, em que as chamadas "universidades de classe mundial" se destacam como referência para o resto do mundo.

\section{CONSIDERAÇÕES FINAIS}

Esta seção apresenta as considerações finais sobre o estudo apresentado, a partir da correlação entre a problemática, o objetivo e as constatações resultantes.

O problema aqui discutido tratou, em síntese, da mercantilização do conhecimento e seu reflexo na definição de qualidade, especialmente na ES, em que as tabelas de classificações e rankings se fortalecem a partir de critérios de produtividade.

A investigação, a partir das reflexões de estudiosos da ES e, especialmente, apoiada em fontes documentais dos organismos internacionais e em páginas da Web institucionais, atingiu o objetivo de traçar um panorama sobre a convergência entre os indicadores de internacionalização, definidos em destacados rankings globais, e os conceitos de qualidade.

Verificou-se que a reflexão sobre qualidade e rankings ultrapassa questões conceituais, o que de fato emerge é o desmerecimento da ES como bem público e de qualidade para a supremacia de uma ES em que um número limitado de IES, em sua maioria privadas, lideram e servem de exemplo de qualidade a ser seguido, em razão de seus dados quantitativos.

Do ponto de vista dos organismos multilaterais, a qualidade tem sido avaliada a partir de diferentes teorias, mas, ao fim e ao cabo, o que impera são interesses políticos e econômicos.

2 Em razão de tratar-se de página da Web, não é possível indicar o número da página. Disponível em: http://ireg-observatory.org/en/index.php/berlin-principles-portuguese. Acesso em: 24 set. 2019. 
A garantia de qualidade no cenário do capitalismo universitário deflagra muito mais uma competição pela melhor colocação das instituições, que buscam valorizar a ES como commodity, do que propriamente alcançar um conceito determinado de "qualidade" de ensino.

As definições quantitativas de publicações e citações internacionais, entre tantos outros indicadores, respaldadas pela técnica de marketing, oferecem a ideia de sucesso de determinadas IES que, supõe-se, promovem a formação dos melhores profissionais para o mercado de trabalho.

Considerando os indicadores atuais, é impossível, pelo menos por enquanto, avaliar a qualidade da educação adequadamente para fins de comparações internacionais. Em teoria, os indicadores não refletem a qualidade na educação, uma vez que não é possível estabelecer um conceito aplicável a todas as IES, indistintamente. Há de se levar em conta como e o que os alunos aprendem, bem como a forma como eles mudam em resultado de suas experiências acadêmicas, e não apenas a produtividade (ALTBACH; HAZELKORN, 2018).

Por fim, não obstante as diferentes críticas verificadas aos rankings, as quais abarcam dúvidas em relação à credibilidade dos indicadores e modos de avaliação e os propósitos a que prestam tais ranqueamentos, fato é que se observa um movimento de aceitação, adaptação e redenção aos mais influentes rankings, de modo a tornarem-se a meta de distintas IES ao redor do mundo.

\section{REFERÊNCIAS}

ALBORNOZ, Mario; OSORIO, Laura. Rankings de universidades: calidad global y contextos locales. CTS - Revista iberoamericana de ciencia, tecnología y sociedad: indicadores, rankings y evaluación, Buenos Aires, v. 13, n. 37, p. 13-51, fev. 2018. Disponível em: http://www.revistacts.net/files/Volumen_13_Numero_37/Finales/CTS37.pdf. Acesso em: 15 ago. 2019.

ALTBACH, Philip G.; HAZELKORN, Ellen. Measuring Education quality in global rankings: what's the likelihood? International Higher Education, [s. I.], v. 95, p. 12-14, 2018. Disponível em: https://ejournals.bc.edu/index.php/ihe/article/view/10721/9194. Acesso em: 28 ago. 2019.

ACADEMIC RANKING OF WORLD UNIVERSITIES. Methodology of Academic Ranking of World Universities 2019. ARWU, 2019. Disponível em: http://www.shanghairanking.com/ ARWU-Methodology-2019.html. Acesso em: 15 ago. 2019. 
BALL, Stephen. Diretrizes políticas globais e relações políticas locais em educação. Currículo sem fronteiras, [s. I.], v. 1, n. 2, p. 99-116, dez. 2001. Disponível em: https:// www.researchgate.net/publication/255629336_Diretrizes_Politicas_Globais_e_Relacoes_ Politicas_Locais_em_Educacao. Acesso em: 30 jul. 2019.

GRUPO BANCO MUNDIAL. Um ajuste justo: análise da eficiência e equidade do gasto público no Brasil. Brasília, 2017. (Síntese, v. I). Disponível em: http://documents.worldbank. org/curated/en/884871511196609355/pdf/121480-REVISED-PORTUGUESE-Brazil-PublicExpenditure-Review-Overview-Portuguese-Final-revised.pdf. Acesso em: 26 ago. 2018.

BARSKY, Osvaldo. La evaluación de la calidad académica en debate: los rankings internacionales de las universidades y el rol de las revistas científicas. 1. ed. Buenos Aires: Teseo; Universidad Abierta Interamericana, 2014. Disponível em: https://www.uai.edu. ar/media/109527/la-evaluación-de-la-calidad-académica-en-debate.pdf. Acesso em: 24 set. 2019.

DÁVILA, Mabel. Rankings universitarios internacionales y conflictos por la regulación de la educación superior. CTS - Revista iberoamericana de ciencia, tecnología y sociedad: indicadores, rankings y evaluación, [s. I.], v. 13, n. 37, p. 67-84, 2018. Disponível em: http://www.revistacts.net/files/Volumen_13_Numero_37/Finales/CTS37.pdf. Acesso em: 24 set. 2019.

DIAS, Marco Antonio Rodrigues. Educação superior como bem público: perspectivas para o centenário da Reforma de Córdoba. Montevideo: Secretaria Executiva AUGM, 2017. Disponível em: www.grupomontevideo.edu.uy. Acesso em: 3 ago. 2018.

DIDRIKSSON, Axel. Contexto global y regional de la educación superior en América latina y el Caribe. In: GAZZOLA, Ana Lúcia; DIDRIKSSON, Axel (Ed.). Tendencias de la Educación Superior en América Latina y el Caribe. Caracas: IESALC-UNESCO, 2008. p. 21-54.

GIL, Antonio Carlos. Como elaborar projetos de pesquisa. 4. ed. São Paulo: Atlas, 2002.

HAZELKORN, Ellen. Rankings and higher education: reframing relationships within and between states. Working paper series, London, maio 2017. Disponível em: https://www. researchcghe.org/publications/working-paper/rankings-and-higher-education-reframingrelationships-within-and-between-states/. Acesso em: 18 ago 2019.

IREG OBSERVATORY ON ACADEMIC RANKING AND EXCELLENCE. Princípios de Berlin para Rankings de Instituições de Educação Superior. IREG, 2006. Disponível em: http://iregobservatory.org/en/index.php/berlin-principles-portuguese. Acesso em: 24 set. 2019. 
MOROSINI, Marilia Costa. Qualidade na educação superior: tendências do século. Estudos em Avaliação Educacional, São Paulo, v. 20, n. 43, p. 165-186, 2009. Disponível em: http://www.fcc.org.br/pesquisa/publicacoes/eae/arquivos/1487/1487.pdf. Acesso em: 27 ago. 2018.

MOROSINI, Marilia Costa. Qualidade da educação superior e contextos emergentes. Avaliação: Revista da Avaliação da Educação Superior, Campinas, v. 19, n. 2, p. 385-405, 2014. Disponível em: http://www.scielo.br/scielo.php?script=sci_arttext\&pid=S1414$40772014000200007 \&$ lng=pt\&tlng=pt. Acesso em: 27 ago. 2018.

MOROSINI, Marilia Costa; FERNANDES, Cleoni Maria Barbosa; LEITE, Denise; FRANCO, Maria Estela Dal Pai; CUNHA, Maria Isabel; Silvia Maria Aguiar Isaia. A qualidade da educação superior e o complexo exercício de propor indicadores. Revista Educação Brasileira, Rio de Janeiro, v. 21, n. 64, p. 13-37, 2016. Disponível em: http://dx.doi. org/10.1590/S1413-24782016216402. Acesso em: 29 ago. 2018.

PERROTA, Daniela. La región sudamericana como arena política para la internacionalización de la universidad. In: ARAYA, Jose María Julio (Ed.). Aportes para los estudios sobre internacionalización de la educación superior en América del Sur. 1. ed. Tandil: UNICEN, 2015. p. 21-50.

QS WORLD UNIVERSITY RANKINGS. Methodology. QS Top Universities, jun. 2019. Disponível em: https://www.topuniversities.com/qs-world-university-rankings/methodology. Acesso em: 5 dez. 2019.

SALMI, Jamil; SAROYAN, Alenoush. Tabelas de classificação como instrumentos políticos: a economia política de credibilidade na educação de $3^{\circ}$ grau. In: TRAD. VERA MULLER (Ed.). Educação superior em um tempo de transformação: novas dinâmicas para a responsabilidade social. Porto Alegre: EDIPUCRS, 2009. p. 174-179.

TIMES HIGHER EDUCATION. Times Higher Education- World University Rankings. About. THE, out. 2019. Disponível em: https://www.timeshighereducation.com/world-universityrankings/about-the-times-higher-education-world-university-rankings. Acesso em: 5 dez. 2019.

TORRES, Carlos Alberto. Ciudadanía global y el rol de las universidades. Revista Latinoamericana de Educación Comparada, Buenos Aires, v. 10, p. 97-110, 2016. Disponível em: http://www.saece.com.ar/relec/revistas/10/art6.pdf. Acesso em: 19 jul. 2019.

UNESCO. Conferência Mundial sobre Ensino Superior 2009: as novas dinâmicas do Ensino Superior e pesquisas para a mudança e o desenvolvimento social. Paris, 2009, p. 1-9. 
UNESCO. Educação 2030: Declaração de Incheon e Marco de Ação para a implementação do Objetivo de Desenvolvimento Sustentável 4: Assegurar a educação inclusiva e equitativa de aprendizagem ao longo da vida para todos. Incheon: UNESCO, 2016. Disponível em: https://unesdoc.unesco.org/ark:/48223/pf0000245656_por. Acesso em: 15 ago. 2019.

UNESCO. Declaraçã o mundial sobre educação superior no século XXI: visão e ação- 1998. UNESCO, 1998. Disponível em: http://www.direitoshumanos.usp.br/index.php/Direitoa-Educação/declaracao-mundial-sobre-educacao-superior-no-seculo-xxi-visao-e-acao. html. Acesso em: 28 ago. 2018.

UNESCO. Plan de Accion CRES 2018-2028. UNESCO, 2018. Disponível em: https://drive. google.com/file/d/1Mr_obMED-yv2RalSeC6L1YeStb1C9tiU/view. Acesso em: 22 jul. 2019.

UVALIC-TRUMBIC, Stamenka. A política internacional de garantia de qualidade e credenciamento: de instrumentos legais a comunidades de prática. In: Tradução de Vera Muller. Educação superior em um tempo de transformação: novas dinâmicas para a responsabilidade social. Porto Alegre: EDIPUCRS, 2009. p. 174.

VERA, María Nevia. Internacionalización de la educación superior: el desafío de la construcción de relaciones sanas. In: ARAYA, José María; OREGIONI, María Soledad (Ed.). Internacionalización de la universidad en el marco de la integración regional. 1. ed. Tandil: Grafikart, 2015. p. 172-82.

\section{Sobre as autoras:}

Marilene Gabriel Dalla Corte: Pós-doutora e doutora em Educação pela Pontifícia Universidade Católica do Rio Grande do Sul (PUCRS). Mestre em Educação e Especialista em Administração e Supervisão Escolar pela Universidade Federal de Santa Maria (UFSM). Especialista em Psicopedagogia pela Faculdades Franciscanas (FAFRA); Graduada em Pedagogia pela Faculdade de Filosofia Ciências e Letras Imaculada Conceição (FIC). Professora adjunta do Departamento de Administração Escolar (ADE), do Centro de Educação da UFSM. Coordenadora e docente no Programa de Pós-Graduação em Políticas Públicas e Gestão Educacional (PPPG) e docente no Programa de Pós-Graduação em Educação (PPGE), ambos do Centro de Educação da UFSM. Líder do Grupo de Estudos e Pesquisas em Políticas Públicas e Gestão Educacional (GESTAR). Vice-líder do Grupo de Estudos e Pesquisa ELOS. Participa do Grupo de Pesquisa UNIVERSITAS/RIES. E-mail: marilenedallacorte@gmail.com, Orcid: http://orcid.org/0000-0001-8272-2944 
Fernanda Ziani Mendes: Mestre em Políticas Públicas e Gestão Educacional pela Universidade Federal de Santa Maria (UFSM). Especialista em Gestão Pública pela Universidade Federal do Rio Grande do Sul (UFRS). Graduada em Direito pela Universidade da Região da Campanha. Participa como estudante no Grupo de Estudos e Pesquisas em Políticas Públicas e Gestão Educacional (GESTAR) da UFSM. Servidora federal e ocupa o cargo de assistente em administração na Universidade Federal do Pampa. E-mail: fernandazianimendes@gmail.com, Orcid: http://orcid.org/0000-0001-9306-9784

Recebido em 9 de outubro de 2019

Aprovado em 14 de fevereiro de 2020 
